\title{
An Assessment of Temporal and Spatial Distribution of Thunder Storms in Iran
}

\author{
Gholam Abbas Fallah Ghalhari*, Fahimeh Shakeri \\ Faculty of Geography and Environmental Sciences, Hakim Sabzevari University, Sabzevar, Iran \\ Email: ${ }^{*}$ ab fa789@yahoo.com
}

Received 15 January 2015; accepted 29 March 2015; published 3 April 2015

Copyright (C) 2015 by authors and Scientific Research Publishing Inc.

This work is licensed under the Creative Commons Attribution International License (CC BY). http://creativecommons.org/licenses/by/4.0/

(c) (i) Open Access

\begin{abstract}
The main purpose of this study is to investigate temporal and spatial distribution of thunderstorm frequency in Iran. In order to do study, observed statistical data of the present weather codes of thunderstorm $(17,29,91-99)$ in 50 synoptic stations around the country were used in a 35 years statistic period (1979-2013). The results of the study showed that the phenomenon occurs mostly in southwest, west and northwest regions of Iran. Thunderstorm occurrence reduces when moving toward east. Maku station in northwest of Iran shows the maximum thunderstorm frequency during the statistical period (mean annual of 31). Jask station in southern Iran (mean annual of 2) has shown minimum thunderstorm occurrence during the statistical period. In the eastern regions of Iran, Torbat Heydarieh station revealed higher frequency than the other stations which was because of high mountains like Qaenat. In terms of temporal distribution, spring showed the highest frequency of the phenomenon. In monthly scale, the maximum frequency of hail downfall happens in April and May. In hourly scale, the maximum occurrence of thunderstorm observed at 12 - 18 p.m. for UTC time.
\end{abstract}

\section{Keywords}

Thunderstorm, Temporal and Spatial Distribution, Present Weather Codes, Iran

\section{Introduction}

Thunderstorm is one of the complex and severe climate risks which results in many casualties in addition to destruction of a great number of crops and utilities in many different parts around the world. Only in 1953-1957, financial damages from thunderstorm were estimated more than 3.6 billion dollars. Thunderstorms take the second rank of natural disasters in terms of damage level to the US economy after Tornados [1]. The dangerous

${ }^{*}$ Corresponding author. 
elements of thunderstorms are as follow:

Updraft and strong turbulence, micro bursts and Gustian fronts, cyclones and tornados, lightening and thunders, hail and heavy rainfall. Two conditions are needed in order to form strong conventions of humidity like those occur in thunderstorm: conditional instabilities and ascending mechanism. Two requirements are needed in order to form strong conventions of humidity like those occur in thunderstorm: conditional instabilities and ascending mechanism. Conditional instabilities mean a particular state which is provided by the environment to form thunderstorm. Once the initial requirements are prepared, thunderstorms can continue their developments. Ascending mechanisms are as follow:

Boundaries between the air mass, fronts, dry lines, sea breeze fronts, Gustian fronts from other thunderstorms and other ascending mechanisms such as atmospheric boundary waves, mountains and surface heating of the regions in a local scale [1].

Many studies have been already conducted in the field of thunderstorms in the world. This phenomenon has been investigated and studied with different approaches.

Wietmann (2003) has performed one of the most significant studies in this field in which mountaineer climatic phenomena are discussed by using a synoptic approach, particularly lightning thunders, hails, heavy rainfalls and other mountaineer phenomena [2]. Esterling (1989) classified the different regions of America, according to the origin and the rainfall level generated by each thunder system and obtained five distinct regions for lightning storms [3].

Esterling (2003) has considered thunderstorm as an important challenge in the 20th century and has counted its environmental economical effects and the corresponding phenomena (hail, flood, storms) on the economy of agriculture section of the US as a disaster [4]. Goutlip (2009) has measured and tested a series of instabilities indices such as Shwualter, ascending, total totals, Eqilibrum surface pressure, SWEAT, K, CAPE and CIN in thunderstorm environments for the northeast of US. In this study, thunderstorm data from Jan to Aug in period 1998-2007 along with high atmosphere data obtained from radio sound technique, were used to forecast thunderstorm in eight regions in northeastern America. The results showed that the best predictor is often ascending index and the second is CAPE index [5].

Haff (1964) has studied the role of thunderstorm, maximum rainfall, temperature, dew point and air fronts and their influences in hail fall distribution in a 50 years period. He believed that hail fall distribution in a small region could be influenced by different climatic elements [6]. Pascal (2005) studied convectional storms on Mediterranean Sea. They related the frequency of thunderstorm in California in late spring and summer to the local mountains and the influence of Sea. In addition, mountains play an important role in formation of local convergence and canalizing the sea breezes. Combination of sea and valley breezes has also increased humidity in the lower layers of the atmosphere and the frequency of thunderstorms [7]. Adam et al. (1999) believed that the development of thunderstorm in South Africa has originated from the strong gradient of temperature, dew point temperature and pressure. They concluded that radar data can be used to predict real-time of development and movement of Thunderstorm [8].

Camophou et al., 2000 investigated phenomena such as hail and thunder storms in northern Italy. They concluded that extreme events such as hail and thunder storms have essential link with the Atlantic disturbances specially disturbances of cold front [9].

Dayan \& coworkers (2001) analyzed the autumn strong storms of east Mediterranean and stated that deepening trough in the middle levels of the atmosphere and its extension to the southern latitudes enhanced subtropical jet and Red Sea trough [10].

Dastjerdi \& Rahimi (2005) have studied the time and statistical features of thunderstorms in Tabriz as a sample of northwestern Iran by using frequency data of thunderstorms in this region. This study showed that in the monthly and seasonal time scale, May and spring have the maximum frequencies of thunderstorm, respectively [11].

Hejazizadeh (2000) studied the variations of two important components of the atmosphere general circulation, i.e. Azour subtropical high pressure and positive vorticity of $500 \mathrm{hPa}$, in order to evaluate lightening storms in west regions of Iran during June (hot period of a year), Jan and Feb (cold periods of a year) in a 30 year statistical period. She compared the obtained data with the results from rainfalls of 18 stations in northwest and west of Iran in different latitudes. She analyzed the atmospheric stability and instability and number of storms together with lightening during 1971-1985 by studying of the above component variations in hot and cold periods of the year and concluded that in the beginning of the hot to cold transition period, increased rainfall directly re- 
lated to the subtropical high pressure retreat [12]. In order to study the frequency of thunderstorms in Iran, Haqiqat Kashani (1991) has noted the maximum number of the storms occurs in the afternoon and around 8 p.m. to 3 a.m. local time and believes that most thunderstorms of Iran are resulted from convective instability of air masses and possibly night storms and less affected by large scale atmospheric systems and cold fronts [13]. Tajbakhsh et al., 2008 investigated the forecast of thunderstorm using decision making tree. The results of the study showed that the large scale indices of thunderstorm occurrence are similar to the atmospheric instabilities and prediction of thunderstorm requires the modeling of regional scale [14].

Iranian Meteorological Institute (2006) studied the difference of various regions in terms of kind of rainfall and also the influence of hail fall on plant growth in Iran. Results showed that by moving from west and northwest to the north, east and northeast regions, the maximum rainfall transfers from May to March and April and also a maximum appears in winter [15].

Omidvar et al., 2001 used daily hail fall data of 14 synoptic stations of Fars province in a period between 2006-2009. They selected three samples of severe hail falls in the region during the statistical period .Using NCEP/NCAR Re-Analysis data, they prepared map of geopotential height, moisture advection, Omega and vorticity. Their results showed that in each selected period, hail fall in Fars province was related to formation and enhancement of cut of low in 500 hpa level in March [16]. Since at present it is not possible to forecast certain atmospheric conditions for a few next months or years and the planning for activities, depending upon climatic conditions, are carried out in a long term scale, recognition of positions disposed to thunderstorm in each region are very important for long term planning and reduction of damages from the phenomenon.

\section{Materials and Methods}

In order to do the study, thunderstorm data used in an hourly (00, 03, 06, 09, 12, 15, 18 and 21), monthly and annual time scale for 50 synoptic stations of Iran during a 35 years statistical period (1979-2013). Among 100 codes relating to the current weather (WW), codes 17, 29, and 91 - 99 which included any thunderstorm occurrence in observation times scale were chosen. Then the statistical parameters of the considered phenomena were extracted in different time scales in each station using SPSS software. At last, in order to show spatial and temporal distributions of thunderstorm phenomenon in Iran, IDW method was used in Arc GIS software. Figure 1 shows Iran topographical map together with the selected stations.

\section{Results and Discussion}

\subsection{Annual Distribution of Thunderstorms in Iran}

Table 1 shows the statistical parameters including average, sum, standard deviation, minimum and maximum of days with thunderstorms in the selected stations during the 35 year statistical period (1979-2013). Regarding the table it is shown that in terms of average, the most frequency of thunderstorms in an annual scale was 31.5 in Maku station and the least was seen in Jask station with 2.2. In general, it can be noted that the mean domain of annual thunderstorm in all stations varied from 2.2 to 31.5 in each year. Maximum annual standard deviation was obtained 18.16 in Maku and the minimum one was 2.13 for Yazd station. Maximum annual thunderstorm was observed 67 in Orumiyeh station. As it can be seen, Maku station experienced 1103 number of thunderstorm and took the first rank in the country. Regarding the frequency of thunderstorm in each station under study, zoning of the phenomenon occurrence was shown in Figure 2, in the 35 years statistical period on the map.

Regarding the figure, it can be noted that regions with the maximum frequency of thunderstorm are centralized in west and northwest regions of Iran. Maku station had the maximum frequency of the phenomenon. Other stations with high frequency included Tabriz, Khooy, Orumiyeh, and Khorramabad .The other regions almost adapted to the dry and desert regions of Iran, showed a relatively low frequency of thunderstorm. As it can be seen in Figure 1, orientation of northwest-southeast of Zagros Mountains was the main factor of the higher frequency of thunderstorms in west and northwest of Iran.

\subsection{Seasonal Distribution of Thunderstorm}

\subsubsection{Spring}

Spatial distribution of thunderstorms in spring is shown in Table 2 and Figure 3. With considering to Table 3, the maximum frequency of thunderstorm belongs to Maku station in northwest of Iran with 675 numbers and the 


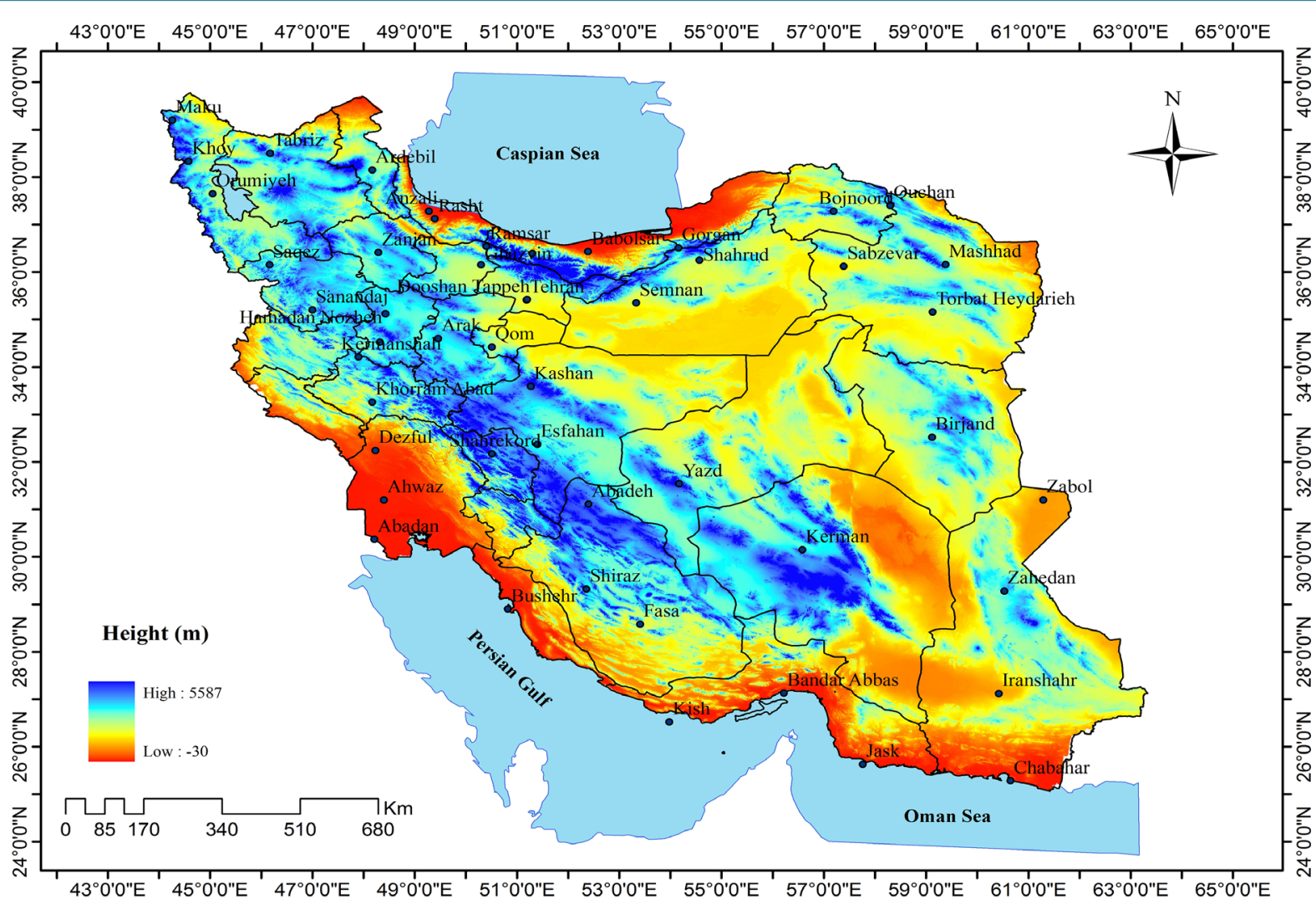

Figure 1. Iran topographical map together with the selected stations.

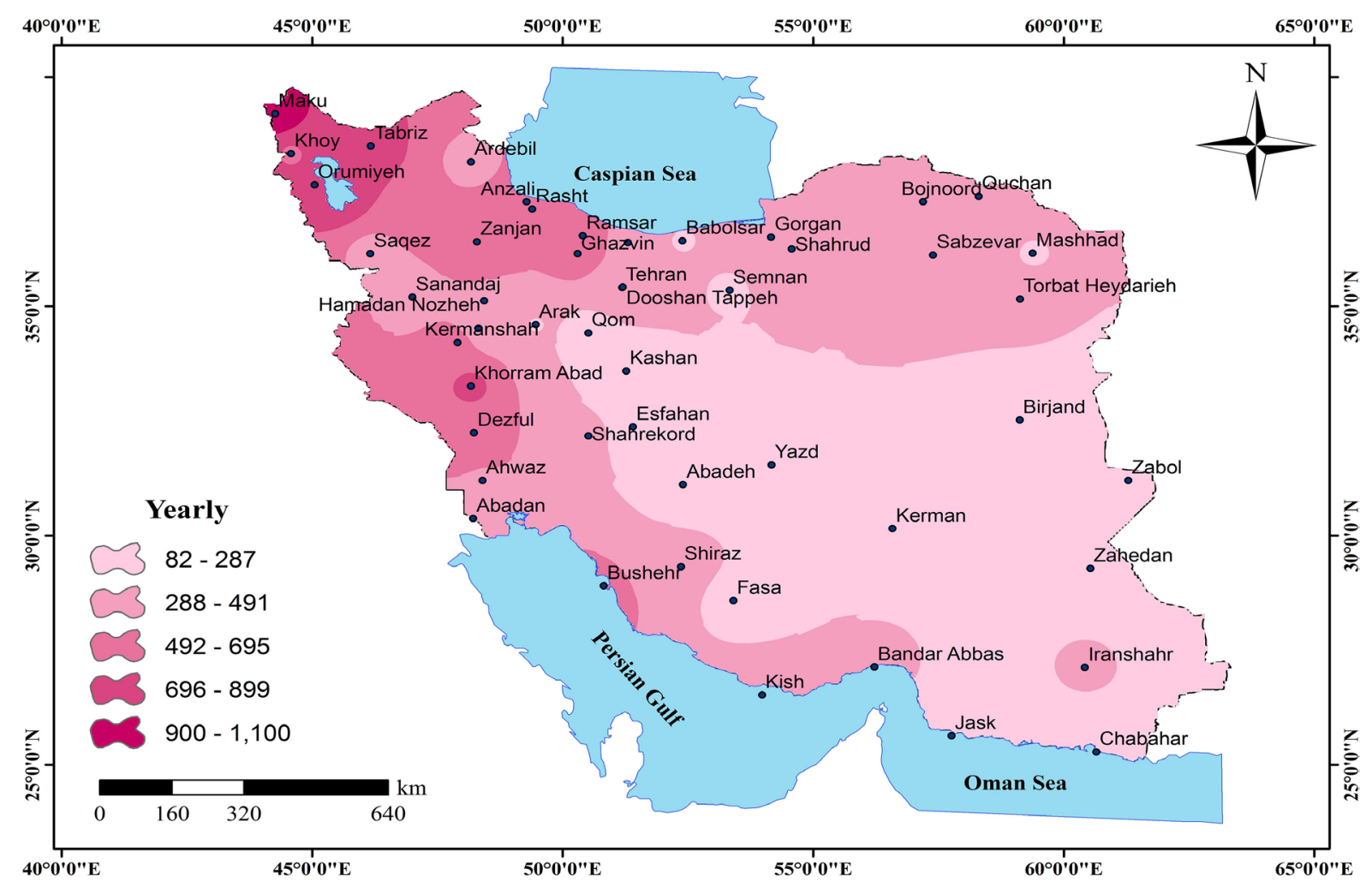

Figure 2. Spatial distribution of annual frequency of thunderstorms in Iran during the statistical period (1979-2013). 
Table 1. Statistical parameters of thunderstorm in the statistical period (1979-2013).

\begin{tabular}{|c|c|c|c|c|c|c|c|c|c|c|c|c|c|}
\hline Station & Mean & Stdev & Skewness & Min & Max & Sum & Station & Mean & Stdev & Skewness & Min & Max & Sum \\
\hline Nowshahr & 12.28 & 11.17 & 1.20 & 1 & 43 & 430 & Anzali & 16.31 & 7.80 & 0.04 & 1.00 & 35.00 & 571 \\
\hline Shahrekord & 10.77 & 6.32 & 0.70 & 1 & 30 & 377 & Arak & 7.85 & 5.25 & 0.52 & 0.00 & 21.00 & 275 \\
\hline $\begin{array}{c}\text { Khorram } \\
\text { Abad }\end{array}$ & 22.4 & 9.80 & -0.143 & 6.00 & 38.00 & 787 & Ardebil & 11.08 & 7.14 & 0.00 & 0.00 & 23.00 & 388 \\
\hline Tehran & 10.97 & 5.05 & -0.020 & 2.00 & 20.00 & 384 & $\begin{array}{l}\text { Bandar } \\
\text { Abbas }\end{array}$ & 10.54 & 6.72 & .95 & 2 & 31 & 369 \\
\hline Khooy & 19.25 & 11.40 & 1.10 & 4.00 & 55.00 & 674 & Birjand & 7 & 3.62 & 0.55 & 1 & 17 & 238 \\
\hline Kermanshah & 18.26 & 9.07 & 1.11 & 8.00 & 42.00 & 621 & Bojnoord & 12.76 & 6.95 & 0.21 & 2 & 29 & 434 \\
\hline Mashhad & 8.26 & 4.80 & 0.68 & 1.00 & 21.00 & 281 & Bushehr & 22.73 & 10.61 & 1.17 & 9 & 58 & 773 \\
\hline Kish & 11.00 & 6.75 & 1.17 & 1.00 & 30.00 & 385 & Chahbahar & 4.17 & 4.78 & 2.44 & 0.00 & 24 & 146 \\
\hline Zanjan & 19.77 & 7.89 & 0.70 & 6.00 & 42.00 & 692 & Esfahan & 3.08 & 2.42 & 0.91 & 0.00 & 9 & 105 \\
\hline Tabriz & 23.11 & 11.69 & 1.29 & 6.00 & 63.00 & 809 & Fasa & 6.02 & 4.88 & 0.84 & 0.00 & 18 & 205 \\
\hline Ramsar & 16.00 & 9.31 & 1.05 & 4.00 & 45.00 & 560 & Ghazvin & 20.20 & 7.94 & 0.77 & 7 & 41 & 687 \\
\hline Orumiyeh & 25.20 & 13.43 & 1.18 & 4.00 & 67.00 & 882 & Qom & 3.73 & 3.42 & 2.16 & 0.00 & 17 & 127 \\
\hline Saqez & 11.37 & 5.63 & 0.26 & 0.00 & 25.00 & 398 & $\begin{array}{c}\text { Hamedan } \\
\text { Airport }\end{array}$ & 8.35 & 6.97 & 1.75 & 0.00 & 32 & 284 \\
\hline Sanandaj & 11.60 & 6.12 & 0.26 & 1.00 & 24.00 & 406 & $\begin{array}{c}\text { Hamedan } \\
\text { Nozheh }\end{array}$ & 13.37 & 5.58 & 0.15 & 3 & 24 & 468 \\
\hline Shiraz & 10.82 & 7.01 & 0.82 & 0.00 & 29.00 & 379 & Kashan & 2.41 & 2.25 & 0.60 & 0.00 & 7 & 82 \\
\hline Zabol & 3.08 & 3.36 & 1.70 & 0.00 & 15.00 & 108 & Kerman & 4.11 & 2.39 & 1.43 & 1 & 12 & 140 \\
\hline Zahedan & 6.40 & 5.68 & 1.63 & 0.00 & 26.00 & 224 & Babolsar & 7.54 & 5.10 & 0.58 & 1 & 19 & 264 \\
\hline Rasht & 15.54 & 9.11 & 0.13 & 1.00 & 35.00 & 544 & Gorgan & 12.67 & 9.31 & 0.40 & 0.00 & 33 & 431 \\
\hline $\begin{array}{c}\text { Torbat } \\
\text { Heydarieh }\end{array}$ & 8.85 & 5.27 & 0.96 & 2.00 & 23.00 & 310 & $\begin{array}{l}\text { Dushan } \\
\text { Tapeh }\end{array}$ & 10.91 & 5.99 & 0.30 & 0.00 & 22 & 371 \\
\hline Semnan & 7.02 & 3.88 & 0.23 & 0.00 & 15.00 & 246 & Jask & 2.23 & 2.75 & 1.10 & 0.00 & 9 & 76 \\
\hline Shahrud & 13.22 & 6.39 & 0.88 & 2.00 & 33.00 & 463 & Iranshahr & 9.32 & 5.63 & 1.03 & 0.00 & 26 & 317 \\
\hline Yazd & 2.51 & 2.13 & 1.03 & 0.00 & 9.00 & 88 & Quchan & 10.35 & 4.45 & 0.94 & 3 & 26 & 352 \\
\hline Abadan & 9.05 & 4.85 & 0.91 & 1.00 & 23.00 & 317 & Sabzevar & 19.17 & 10.11 & 0.31 & 0.00 & 43 & 652 \\
\hline Abadeh & 5.02 & 4.14 & 0.58 & 0.00 & 14.00 & 176 & Dezful & 8.50 & 4.64 & 0.50 & 1 & 20 & 289 \\
\hline Ahwaz & 13.74 & 7.60 & 0.44 & 1.00 & 33.00 & 481 & Maku & 31.51 & 18.16 & -0.52 & 0.00 & 59 & 1103 \\
\hline
\end{tabular}

minimum was seen in Jask station in southeast of Iran with two numbers. Regarding to Figure 3(a), the maximum frequency of thunderstorms happen in northwest of the country because western hillside of Zagros Mountains helps the air ascending and also the moisture content in this season is available for convection.

\subsubsection{Summer}

Respecting to Table 2 it is seen that the maximum thunderstorm frequency belongs to Maku station in northwest of the country with 356 numbers and the minimum was seen in Jask and Bushehr stations (in southeast and southwest of the country, respectively) with one numbers. The spatial distribution of thunderstorm in spring is 
Table 2. Seasonal distribution of thunderstorm during the statistical period (1979-2013).

\begin{tabular}{|c|c|c|c|c|c|c|c|c|c|}
\hline Station & Winter & Spring & Summer & Autumn & Station & Winter & Spring & Summer & Autumn \\
\hline Nowshahr & 16 & 150 & 145 & 109 & Anzali & 11 & 290 & 176 & 86 \\
\hline Shahrekord & 62 & 167 & 34 & 114 & Arak & 44 & 182 & 63 & 37 \\
\hline Khorram Abad & 166 & 321 & 26 & 271 & Ardebil & 10 & 250 & 104 & 25 \\
\hline Tehran & 40 & 209 & 71 & 64 & Bandar Abbas & 172 & 39 & 27 & 131 \\
\hline Khooy & 12 & 440 & 179 & 44 & Birjand & 90 & 98 & 10 & 40 \\
\hline Kermanshah & 97 & 302 & 25 & 210 & Bojnoord & 28 & 292 & 81 & 33 \\
\hline Mashhad & 32 & 217 & 15 & 17 & Bushehr & 302 & 99 & 1 & 371 \\
\hline Kish & 190 & 57 & 12 & 126 & Chahbahar & 52 & 28 & 45 & 53 \\
\hline Zanjan & 19 & 427 & 170 & 76 & Esfahan & 15 & 63 & 14 & 11 \\
\hline Tabriz & 15 & 534 & 201 & 75 & Fasa & 73 & 55 & 41 & 39 \\
\hline Ramsar & 14 & 246 & 196 & 104 & Ghazvin & 53 & 420 & 121 & 93 \\
\hline Orumiyeh & 17 & 565 & 173 & 118 & Qom & 7 & 90 & 13 & 17 \\
\hline Saqez & 31 & 237 & 45 & 87 & Hamedan Airport & 11 & 174 & 30 & 69 \\
\hline Sanandaj & 35 & 252 & 30 & 89 & Hamedan Nozheh & 31 & 296 & 65 & 76 \\
\hline Shiraz & 122 & 109 & 21 & 87 & Kashan & 6 & 56 & 10 & 10 \\
\hline Zabol & 51 & 39 & 3 & 16 & Kerman & 12 & 100 & 31 & 17 \\
\hline Zahedan & 43 & 121 & 20 & 40 & Babolsar & 7 & 52 & 118 & 88 \\
\hline Rasht & 18 & 273 & 198 & 80 & Gorgan & 14 & 132 & 190 & 81 \\
\hline Torbat Heydarieh & 58 & 169 & 10 & 23 & Dushan Tapeh & 42 & 199 & 56 & 67 \\
\hline Semnan & 15 & 124 & 62 & 17 & Jask & 28 & 2 & 1 & 17 \\
\hline Shahrud & 34 & 265 & 103 & 57 & Iranshahr & 74 & 112 & 75 & 43 \\
\hline Yazd & 12 & 67 & 5 & 4 & Quchan & 25 & 174 & 32 & 22 \\
\hline Abadan & 91 & 88 & 3 & 135 & Dezful & 228 & 154 & 7 & 252 \\
\hline Abadeh & 22 & 118 & 14 & 22 & Sabzevar & 49 & 186 & 26 & 29 \\
\hline Ahwaz & 128 & 126 & 9 & 219 & Maku & 10 & 675 & 356 & 49 \\
\hline
\end{tabular}

shown in Figure 3(b). According to the figure, in the summer regions with the maximum thunderstorms are centralized in northwest (Maku station). As it can be seen, the thunderstorm frequency in this season dramatically decreases. Predominance of Azour subtropical high pressure in the summer and most regions of the country prevent strong convention and thunderstorm formation.

\subsubsection{Autumn}

Regarding to Table 2 maximum frequency of thunderstorm in the autumn relates to Bushehr (371 numbers) and Khorramabad stations (271 numbers) and the minimum is seen in Yazd station (4 numbers). Figure 3(c) shows spatial distribution of thunderstorms in autumn. As it can be observed, regions with maximum thunderstorms are centered in west and southwest of Iran. In this season, retreat of Azour subtropical high pressure toward lower latitudes and mountains and also proximity to Mediterranean Sea and Persian Gulf has provided conditions to form convention and thunderstorm in northwest and southwest regions of the country.

\subsubsection{Winter}

Regarding to Table 2 it is seen that in the winter the maximum frequency of thunderstorms belongs to Bushehr 

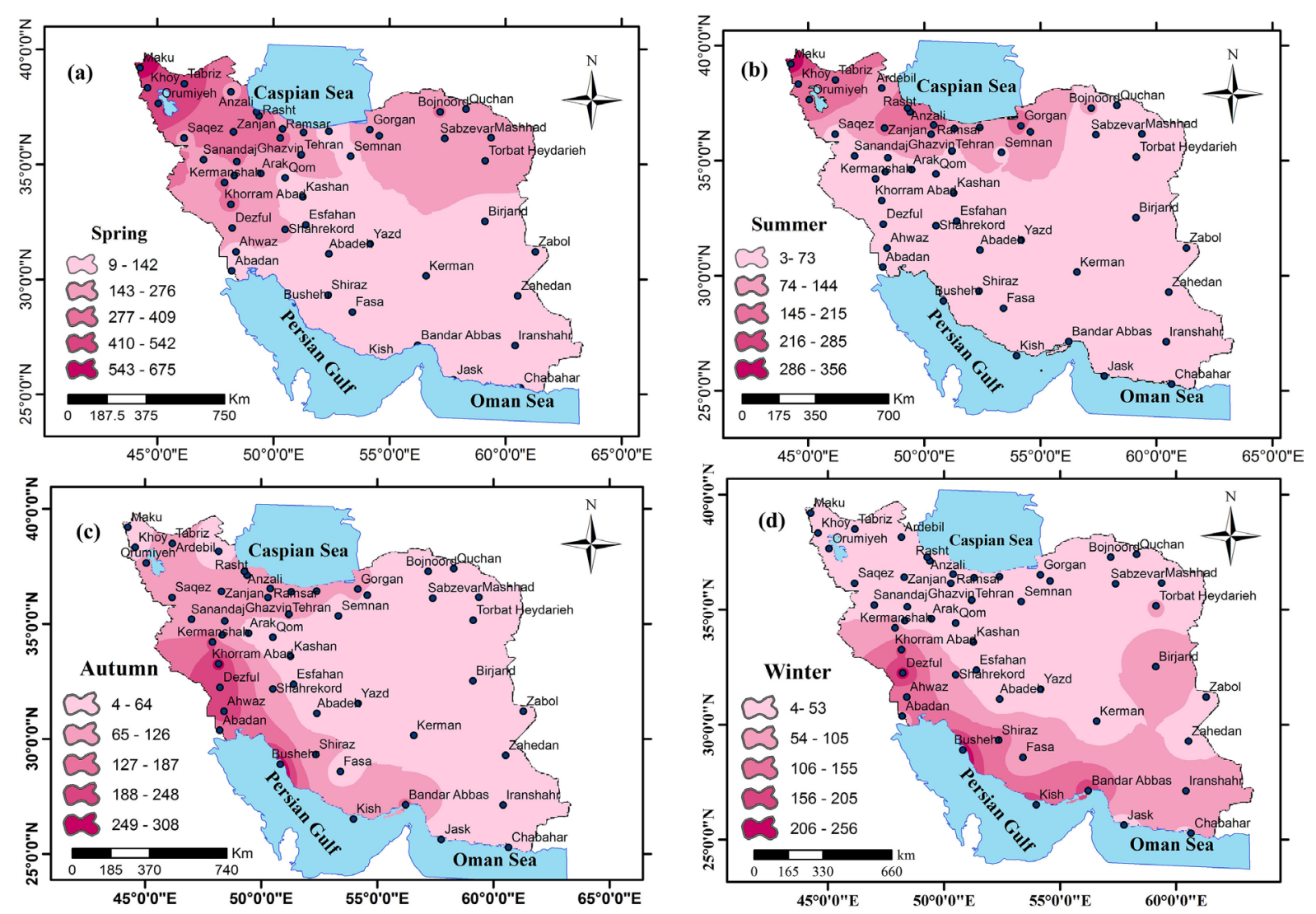

Figure 3. Spatial distribution of thunderstorms in different seasons.

(302 numbers) and Dezful stations (228 numbers) and the minimum was seen in Kashan station with 6 numbers. The spatial distribution of thunderstorm in the winter is demonstrated in Figure $3(\mathrm{~d})$. According to the figure it is seen that in the winter regions with maximum thunderstorms are centered in southwest parts. The thunderstorm region in this season is extended to the eastern parts of Iran. Lack of presence of Azor subtropical high pressure, proximity to the sea, sea to land flows, high temperature and surface heating provide the best conditions for thunderstorm formation in these regions.

\subsection{Monthly Distribution of Thunderstorm}

Study of frequency of thunderstorm in each month (Table 3 and Figure 4) shows that thunderstorms occur more in April, May and June than in the other months during the studied statistical period (1979-2013). To clarify the issue, the spatial distribution of thunderstorms is discussed in the following:

Regarding to Table 3, the maximum frequency in January was seen in Bushehr station with 117 numbers and the minimum was observed 0 numbers for Khoy, Bojnoord and Ardebil. In this month, regions with the maximum occurrence of thunderstorms are centralized in south to southwest parts of the country (Figure 4(a)).

Dezful station had the highest frequency of thunderstorm after Bushehr. Other regions have relative low frequencies. In Feb (Figure 4(b)), the maximum frequency of thunderstorm was observed in Bushehr station with 68 numbers and the minimum was seen in Qom, Kashan and Ardebil stations with 0 numbers. The thunderstorm frequency was seen more in Feb than in Jan and involved the eastern regions of Iran. In this month, maximum thunderstorm frequency was seen in southeast to southwest regions of the country and in eastern part of Iran Birjand station had the maximum frequency because of the high mountains like Qaenat and Birjand mountains. In this month, Dezful, Bushehr, Bandarabbas, Kish and Iranshahr revealed high frequency of thunderstorm. In March (Figure 4(c)) the maximum frequency of thunderstorm occurrence was related to Bushehr station with 117 numbers and the minimum number was for Kerman and Babolsar with frequency 1. Regarding to Figure 4(c), the maximum regions of thunderstorms are found in west to south regions of the country. In this month the 



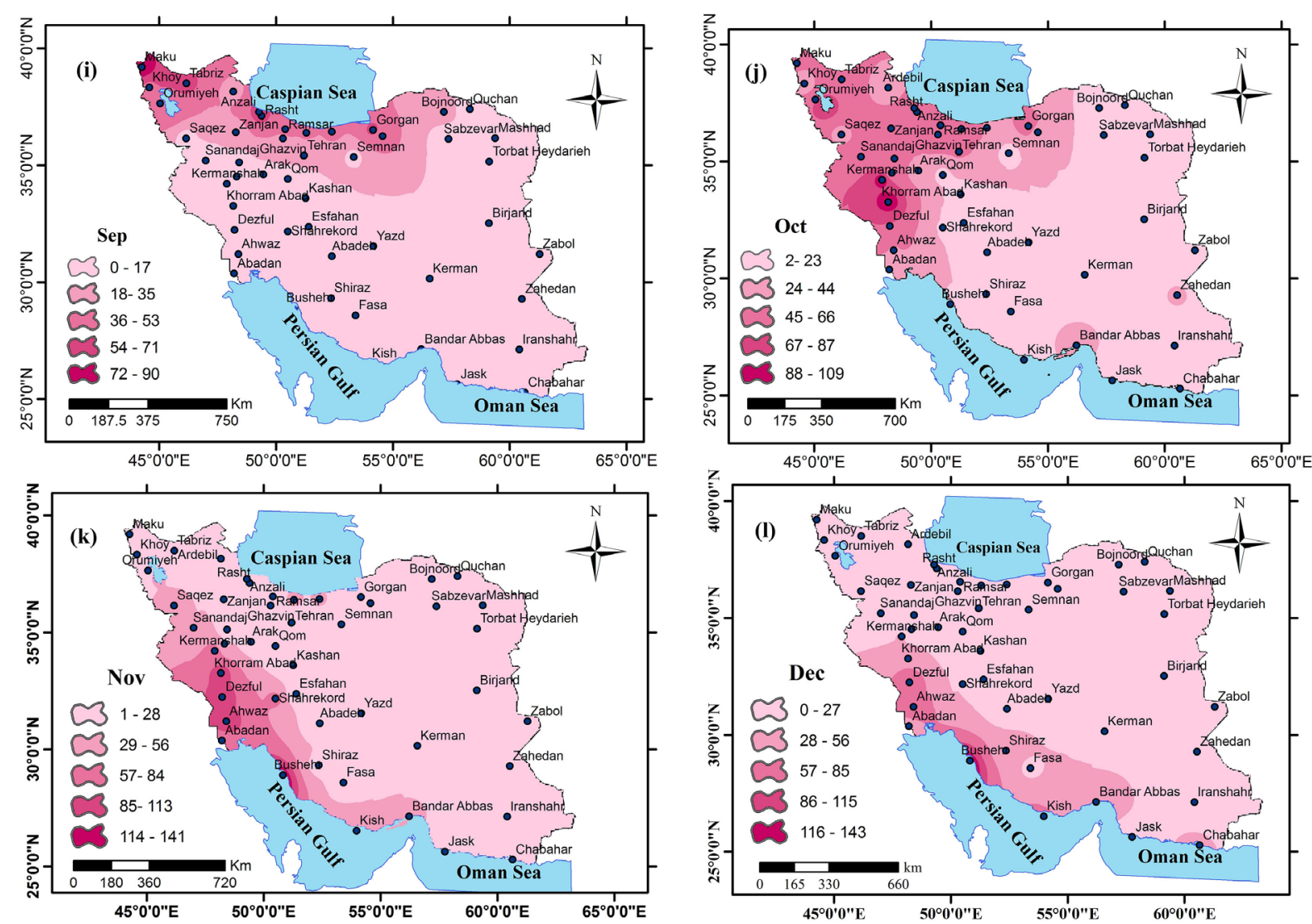

Figure 4. Spatial distribution of thunderstorm in different months.

Table 3. Monthly distribution of thunderstorms in different stations during the statistical period (1979-2013).

\begin{tabular}{|c|c|c|c|c|c|c|c|c|c|c|c|c|}
\hline Station & Jan & Feb & March & Apr & May & June & July & Aug & Sep & Oct & Nov & Dec \\
\hline Nowshahr & 6 & 8 & 2 & 18 & 66 & 66 & 62 & 41 & 42 & 61 & 35 & 13 \\
\hline Shahrekord & 17 & 20 & 25 & 72 & 74 & 21 & 9 & 11 & 14 & 22 & 64 & 28 \\
\hline Khorram Abad & 34 & 33 & 99 & 184 & 121 & 16 & 10 & 8 & 8 & 109 & 104 & 58 \\
\hline Tehran & 2 & 8 & 30 & 66 & 98 & 45 & 32 & 19 & 20 & 44 & 13 & 7 \\
\hline Khooy & 0 & 4 & 8 & 73 & 199 & 168 & 77 & 51 & 51 & 36 & 6 & 2 \\
\hline Kermanshah & 13 & 24 & 60 & 156 & 136 & 10 & 8 & 5 & 12 & 102 & 76 & 32 \\
\hline Mashhad & 1 & 4 & 27 & 69 & 104 & 44 & 5 & 5 & 5 & 8 & 4 & 5 \\
\hline Kish & 62 & 52 & 76 & 45 & 9 & 3 & 8 & 4 & 0 & 5 & 52 & 69 \\
\hline Zanjan & 1 & 7 & 12 & 114 & 197 & 116 & 90 & 54 & 26 & 54 & 20 & 2 \\
\hline Tabriz & 4 & 4 & 7 & 104 & 240 & 190 & 101 & 41 & 59 & 65 & 8 & 2 \\
\hline Ramsar & 3 & 7 & 4 & 37 & 109 & 100 & 87 & 62 & 47 & 69 & 26 & 9 \\
\hline Orumiyeh & 3 & 2 & 12 & 94 & 301 & 170 & 72 & 48 & 53 & 81 & 31 & 6 \\
\hline Saqez & 4 & 12 & 15 & 77 & 118 & 42 & 15 & 19 & 11 & 38 & 40 & 9 \\
\hline Sanandaj & 2 & 5 & 28 & 122 & 102 & 28 & 17 & 6 & 7 & 48 & 30 & 11 \\
\hline
\end{tabular}




\section{Continued}

\begin{tabular}{|c|c|c|c|c|c|c|c|c|c|c|c|c|}
\hline Shiraz & 21 & 24 & 77 & 63 & 40 & 6 & 8 & 11 & 2 & 20 & 20 & 47 \\
\hline Zabol & 5 & 14 & 32 & 20 & 15 & 4 & 1 & 1 & 1 & 5 & 8 & 3 \\
\hline Zahedan & 5 & 10 & 28 & 59 & 56 & 6 & 8 & 6 & 6 & 25 & 10 & 5 \\
\hline Rasht & 1 & 4 & 13 & 59 & 115 & 99 & 79 & 59 & 60 & 54 & 19 & 7 \\
\hline Torbat Heydarieh & 8 & 15 & 35 & 71 & 70 & 28 & 6 & 3 & 1 & 7 & 8 & 8 \\
\hline Semnan & 1 & 1 & 13 & 26 & 71 & 27 & 29 & 21 & 12 & 11 & 2 & 4 \\
\hline Shahrud & 1 & 7 & 26 & 62 & 129 & 74 & 23 & 40 & 40 & 37 & 10 & 10 \\
\hline Yazd & 1 & 1 & 10 & 29 & 31 & 7 & 5 & 0 & 0 & 2 & 1 & 1 \\
\hline Abadan & 22 & 32 & 37 & 49 & 35 & 4 & 0 & 1 & 2 & 30 & 65 & 40 \\
\hline Abadeh & 1 & 1 & 20 & 35 & 61 & 22 & 8 & 4 & 2 & 14 & 5 & 3 \\
\hline Ahwaz & 32 & 35 & 61 & 76 & 41 & 9 & 2 & 2 & 5 & 44 & 98 & 77 \\
\hline Anzali & 3 & 2 & 6 & 57 & 123 & 110 & 65 & 49 & 62 & 58 & 15 & 13 \\
\hline Arak & 2 & 6 & 36 & 68 & 87 & 27 & 28 & 25 & 10 & 26 & 10 & 1 \\
\hline Ardebil & 0 & 0 & 10 & 28 & 130 & 92 & 39 & 35 & 30 & 22 & 3 & 0 \\
\hline Bandar Abbas & 33 & 62 & 77 & 19 & 13 & 7 & 6 & 16 & 5 & 36 & 38 & 57 \\
\hline Birjand & 16 & 26 & 48 & 42 & 47 & 9 & 2 & 2 & 6 & 7 & 9 & 24 \\
\hline Bojnoord & 0 & 7 & 21 & 77 & 140 & 75 & 33 & 22 & 26 & 15 & 16 & 2 \\
\hline Bushehr & 117 & 68 & 117 & 74 & 23 & 2 & 0 & 1 & 0 & 26 & 171 & 174 \\
\hline Chahbahar & 32 & 11 & 9 & 8 & 8 & 12 & 20 & 24 & 1 & 8 & 11 & 34 \\
\hline Esfahan & 1 & 3 & 11 & 26 & 24 & 13 & 5 & 5 & 4 & 3 & 8 & 0 \\
\hline Fasa & 9 & 19 & 45 & 27 & 22 & 6 & 13 & 23 & 5 & 3 & 13 & 23 \\
\hline Ghazvin & 5 & 11 & 37 & 135 & 190 & 95 & 54 & 36 & 31 & 63 & 24 & 6 \\
\hline Qom & 1 & 0 & 6 & 36 & 40 & 14 & 4 & 1 & 8 & 14 & 3 & 0 \\
\hline Hamedan Airport & 1 & 2 & 8 & 55 & 92 & 27 & 15 & 10 & 5 & 43 & 23 & 3 \\
\hline Hamedan Nozheh & 1 & 1 & 29 & 100 & 150 & 46 & 27 & 28 & 10 & 58 & 17 & 1 \\
\hline Kashan & 1 & 0 & 5 & 16 & 31 & 9 & 3 & 5 & 2 & 8 & 2 & 0 \\
\hline Kerman & 6 & 5 & 1 & 23 & 42 & 35 & 15 & 11 & 5 & 11 & 6 & 0 \\
\hline Babolsar & 2 & 3 & 1 & 2 & 22 & 28 & 40 & 37 & 41 & 44 & 33 & 11 \\
\hline Gorgan & 2 & 4 & 8 & 13 & 64 & 55 & 62 & 68 & 60 & 56 & 19 & 6 \\
\hline Dushan Tapeh & 5 & 6 & 31 & 72 & 78 & 49 & 23 & 17 & 16 & 48 & 17 & 2 \\
\hline Jask & 13 & 4 & 11 & 2 & 0 & 0 & 0 & 0 & 0 & 1 & 4 & 12 \\
\hline Iranshahr & 4 & 40 & 30 & 33 & 42 & 37 & 39 & 30 & 6 & 23 & 5 & 15 \\
\hline Quchan & 1 & 6 & 19 & 57 & 70 & 47 & 17 & 5 & 10 & 11 & 4 & 7 \\
\hline Dezful & 81 & 55 & 92 & 105 & 42 & 7 & 1 & 3 & 3 & 66 & 103 & 83 \\
\hline Sabzevar & 2 & 14 & 33 & 64 & 93 & 29 & 10 & 9 & 7 & 13 & 8 & 8 \\
\hline Maku & - & - & 4 & 77 & 268 & 330 & 153 & 113 & 90 & 46 & 2 & 1 \\
\hline
\end{tabular}


development of thunderstorm increased and extended to the northeast regions. Dezful, Bushehr and Khorramabad stations had the highest frequencies of this phenomenon. Another group with high frequency includes Kish, Shiraz and Bandarabbs stations. In April (Figure 4(d)) the highest frequency related to Khorramabad with 184 numbers and the least was seen in Jask and Babolsar with 2 numbers. As it is shown, the frequency of thunderstorm occurrences is centralized in west regions of the country. Khorramabad and Kermanshah stations had the highest frequency of thunderstorm and Ghazvin, Zanjan and Sanandaj are in the next rank. In May (Figure 4(e)) the highest frequency of thunderstorm was related to Orumiyeh station in northwest of Iran with 301 numbers and the minimum number was seen in Jask station in southeast of Iran with frequency of zero.

According to Figure 4(e), in this month south, central and almost east regions experience the minimum numbers of thunderstorm and the northwest regions experience the least numbers. Maku, Tabriz and Orumiyeh had the highest frequency of this phenomenon and Ghazvin, Zanjan and Khooy take the second rank in this month. In June (Figure 4(f)), maximum frequency of thunderstorm relates to Maku station in northwest of Iran with about 330 numbers and the minimum relates to Jask in southeast of Iran with 0 number. In July (Figure 4(g)) the maximum frequency of thunderstorm related to Maku with 153 numbers and the minimum was for Abadan, Bushehr and Jask with frequency of 0 numbers. In this month Iranshahr and Bojnoord, in southeast and northeast, respectively, showed the maximum frequency. In northwest regions of the country, Maku had the maximum frequency of thunderstorm. Tabriz also showed a high frequency. In August (Figure 4(h)) the maximum frequency of thunderstorm related to Maku with 113 numbers and the minimum was seen in Yazd and Jask with 0 numbers. In August, regions with maximum thunderstorm are centralized in northwest parts and the frequency of the storm is extended to the central regions. In this month, Maku station had the highest frequency of thunderstorm. In September (Figure 4(i)) regions with the highest frequency of thunderstorm are centralized in north and northwest regions.

The maximum frequency of thunderstorm was related to Maku station with 90 numbers and the minimum was seen in Kish, Yazd and Jask with frequency of 0 numbers. The other group with relative high frequency included Tabriz, Khooy, Anzali, Rasht and Gorgan. In October (Figure 4(j)) regions with the maximum thunderstorm are seen in west parts. In this month, the maximum frequency related to Khorramabad station with 109 numbers and the minimum was seen in Jask station with 0 numbers. In this month, Ramsar and Orumiyeh had the highest frequency. In November (Figure 4(k)) Bushehr station had the maximum frequency of thunderstorm (171 numbers) and the minimum was observed in Yazd station (1 number). In November, Bushehr station showed the maximum frequency of thunderstorm. The other group with relatively high frequency was Khorramabad Dezful and Ahvaz. In December (Figure 4(I)) the maximum frequency was seen in Bushehr station (174 numbers) and the minimum was seen in Isfahan, Ardebil, Qom, Kashan and Kerman stations (0 numbers). As it can be seen, in this month regions with maximum frequency of thunderstorm are centralized in south to southwest parts of the country. In this month, Bushehr station showed the maximum frequency of thunderstorm occurrence.

\subsection{Hourly Distribution of Thunderstorms}

Table 4 and Figure 5 show thunderstorm occurrence in the main synoptic hours during the 35 years statistical period (1979-2013). As it can be seen in this table, thunderstorm frequency is higher for 12, 15, and 18 at UTC time than at the other times. To clarify the issue, spatial distribution of thunderstorms in different times is discussed briefly. Regarding to Table 4, for 00 at UTC, maximum frequency of thunderstorm relates to Bushehr station (122 numbers) and the minimum frequency is for Abadeh station (2 numbers).

Regarding to Figure 5(a) for 00 at UTC, Dezful and Bushehr stations in southwest have the maximum frequency of thunderstorm. For 03 at UTC, the maximum frequency was seen in Bushehr in southwest of Iran (149 numbers) and minimum was seen in Kashan in the centeral regions (0 number). As it can be seen in Figure 5(b) Bushehr station in southwest of the country has the maximum frequency of thunderstorm. For 06 UTC, like 00 and 03 at UTC, maximum frequency of thunderstorm was related to Bushehr station in west foothills of the Zagros mountains and Persian Gulf coasts (90 number) and the minimum was seen in Qom, Zahedan and Kashan stations (1 number) which are located in the margins of central desert of Iran.

Regarding to Figure 5(c), for 06 at UTC time, regions with maximum thunderstorm are seen in southwest and west parts. As it can be observed, at this time Bushehr has the maximum thunderstorm frequency. For 09 at UTC, maximum frequency of thunderstorm belongs to Maku station (132 numbers) and the minimum is seen in 

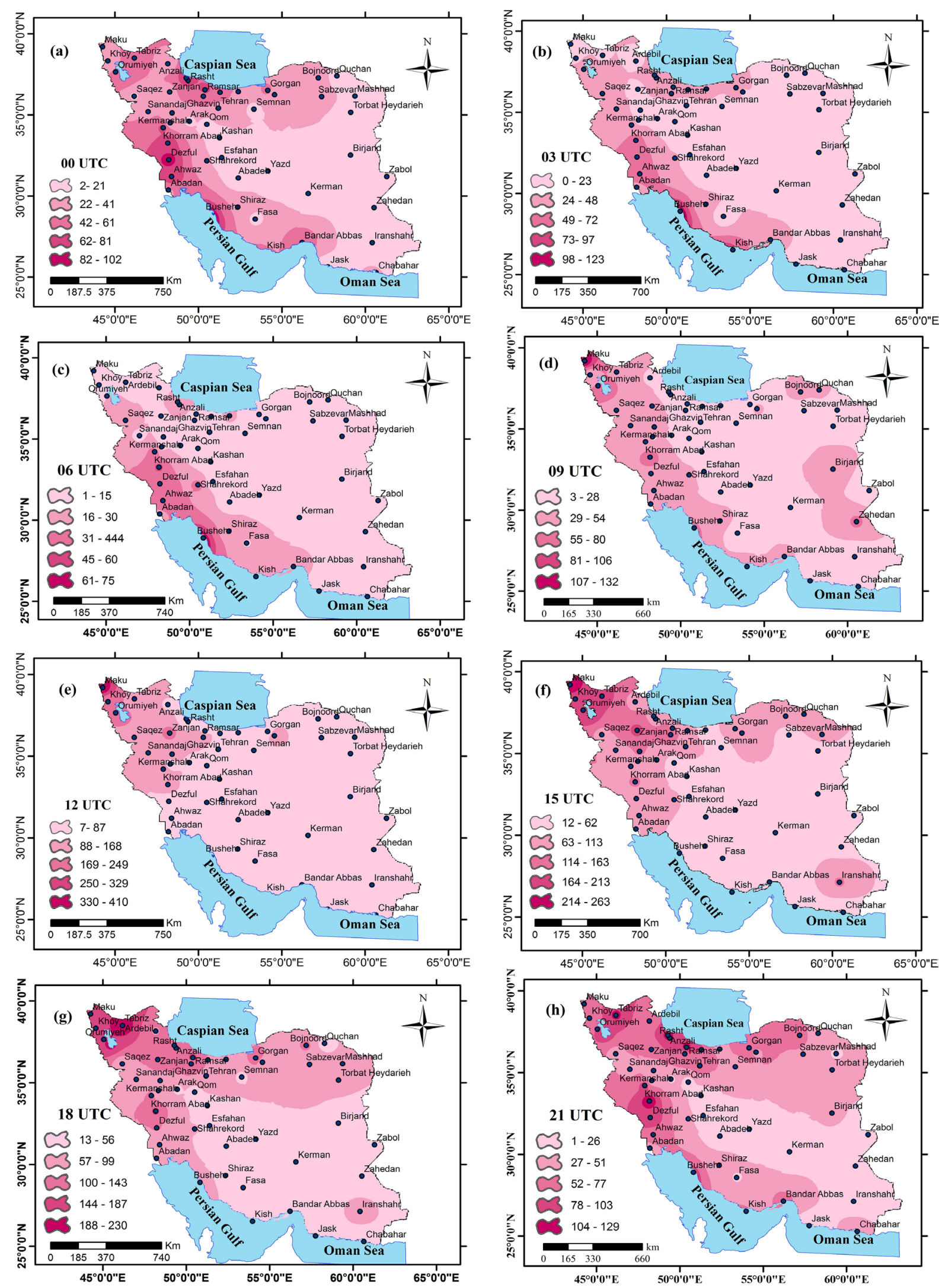

Figure 5. Spatial distribution of thunderstorm against the synoptic hours. 
Table 4. Temporal distribution of thunderstorm during the studied statistical period (1979-2013).

\begin{tabular}{|c|c|c|c|c|c|c|c|c|c|c|c|c|c|c|c|c|c|}
\hline Station & 00 & 03 & 06 & 09 & 12 & 15 & 18 & 21 & Station & 00 & 03 & 06 & 09 & 12 & 15 & 18 & 21 \\
\hline Nowshahr & 48 & 36 & 14 & 20 & 53 & 74 & 96 & 80 & Anzali & 82 & 45 & 23 & 14 & 46 & 108 & 142 & 111 \\
\hline Shahrekord & 25 & 28 & 35 & 43 & 74 & 80 & 60 & 32 & Arak & 16 & 11 & 10 & 26 & 78 & 64 & 46 & 21 \\
\hline Khorram Abad & 82 & 62 & 49 & 75 & 114 & 121 & 155 & 129 & Ardebil & 24 & 16 & 5 & 26 & 80 & 92 & 95 & 51 \\
\hline Tehran & 38 & 16 & 11 & 21 & 53 & 82 & 104 & 59 & BandarAbbas & 62 & 43 & 27 & 32 & 39 & 58 & 47 & 61 \\
\hline Khooy & 23 & 24 & 5 & 30 & 171 & 187 & 179 & 56 & Birjand & 13 & 10 & 7 & 45 & 52 & 35 & 46 & 29 \\
\hline Kermanshah & 71 & 46 & 39 & 41 & 126 & 114 & 108 & 90 & Bojnoord & 36 & 17 & 9 & 37 & 85 & 76 & 108 & 66 \\
\hline Mashhad & 21 & 6 & 5 & 19 & 73 & 75 & 58 & 24 & Bushehr & 122 & 149 & 90 & 75 & 60 & 62 & 101 & 114 \\
\hline Kish & 48 & 93 & 32 & 39 & 45 & 45 & 54 & 59 & Chahbahar & 24 & 15 & 8 & 10 & 10 & 18 & 26 & 31 \\
\hline Zanjan & 31 & 15 & 9 & 47 & 221 & 193 & 124 & 52 & Esfahan & 6 & 2 & 6 & 10 & 23 & 31 & 19 & 6 \\
\hline Tabriz & 57 & 23 & 9 & 52 & 132 & 188 & 230 & 109 & Fasa & 18 & 10 & 15 & 11 & 44 & 44 & 41 & 25 \\
\hline Ramsar & 75 & 29 & 11 & 17 & 47 & 104 & 155 & 122 & Ghazvin & 46 & 25 & 14 & 32 & 194 & 187 & 134 & 55 \\
\hline Orumiyeh & 65 & 36 & 19 & 73 & 192 & 196 & 199 & 92 & Qom & 10 & 8 & 1 & 6 & 30 & 34 & 30 & 15 \\
\hline Saqez & 19 & 38 & 27 & 33 & 88 & 91 & 62 & 40 & Hamedan Airport & 19 & 12 & 11 & 23 & 52 & 73 & 65 & 29 \\
\hline Sanandaj & 38 & 26 & 12 & 42 & 98 & 91 & 61 & 41 & Hamedan Nozheh & 35 & 19 & 9 & 43 & 117 & 125 & 89 & 31 \\
\hline Shiraz & 41 & 30 & 25 & 41 & 57 & 54 & 50 & 41 & Kashan & 3 & 0 & 1 & 3 & 28 & 21 & 22 & 4 \\
\hline Zabol & 10 & 4 & 4 & 6 & 14 & 23 & 33 & 15 & Kerman & 6 & 4 & 2 & 23 & 41 & 40 & 15 & 9 \\
\hline Zahedan & 5 & 5 & 1 & 59 & 60 & 58 & 26 & 10 & Babolsar & 41 & 37 & 19 & 15 & 17 & 28 & 65 & 42 \\
\hline Rasht & 63 & 46 & 29 & 19 & 60 & 99 & 144 & 105 & Gorgan & 50 & 36 & 13 & 18 & 40 & 78 & 117 & 76 \\
\hline Torbat Heydarieh & 17 & 10 & 7 & 26 & 59 & 44 & 59 & 31 & Dushan Tapeh & 42 & 21 & 10 & 19 & 58 & 68 & 85 & 61 \\
\hline Semnan & 13 & 10 & 10 & 14 & 52 & 37 & 46 & 36 & Jask & 8 & 6 & 2 & 6 & 3 & 7 & 9 & 6 \\
\hline Shahrud & 20 & 23 & 5 & 33 & 131 & 112 & 91 & 48 & Iranshahr & 10 & 7 & 5 & 12 & 54 & 118 & 79 & 25 \\
\hline Yazd & 3 & 3 & 5 & 8 & 25 & 27 & 16 & 1 & Quchan & 12 & 8 & 7 & 33 & 87 & 77 & 42 & 31 \\
\hline Abadan & 35 & 33 & 22 & 27 & 32 & 61 & 76 & 31 & Sabzevar & 26 & 11 & 8 & 12 & 57 & 50 & 74 & 52 \\
\hline Abadeh & 2 & 6 & 5 & 24 & 66 & 47 & 21 & 5 & Dezful & 96 & 73 & 45 & 51 & 74 & 103 & 102 & 106 \\
\hline Ahwaz & 75 & 74 & 46 & 37 & 42 & 66 & 72 & 70 & Maku & 40 & 14 & 14 & 132 & 410 & 263 & 158 & 68 \\
\hline
\end{tabular}

Kashan station (3 numbers). As it can be seen in Figure 5(d), for 09 at UTC, the regions with the maximum thunderstorm occurrence has been transferred from southwest to northwest of the country.

At this time, Maku had the maximum thunderstorm frequency. However, the frequency has been extended to the east and northeast parts of the country. For 12 at UTC, the maximum thunderstorm frequency belongs to Maku station (410 NUMBERS) and the minimum was seen in Jask station (3 NUMBERS). As it can be observed in Figure 4(e), regions with maximum thunderstorm frequency are seen in northwest and almost in west parts of the country. For 15 at UTC, the maximum thunderstorm frequency was seen in Maku station (263 numbers) and the minimum was seen in Jask station (7 numbers). According to Figure 5(f), for 15 at UTC, regions with maximum thunderstorm frequencies are seen in north, northeast, northwest, west and southeast parts of the country.

For 18 at UTC, the maximum thunderstorm frequency relates to Tabriz station (230 numbers) and the minimum is seen in Jask station (9 numbers). As it can be observed in Figure 5(g) for 18 at UTC, regions with maximum thunderstorm frequency are seen in north, northeast, northwest, west and southeast of the country. 
For 21 at UTC, the maximum thunderstorm frequency was related to Khorramabadstation (129 numbers) and the minimum was seen in Yazd station (1 numbers). According to Figure 5(h), for 21 at UTC, regions with maximum frequency of thunderstorm are centralized in north, northeast, northwest, west, southeast, and somewhat center of Iran. Ghazvin, Ramsar, Rasht, Anzali, Tabriz, Khorramabadand Dezful stations had the maximum thunderstorm occurrence. As it was noted, thunderstorm frequencies depended upon availability of ascending mechanisms and conditional instabilities. Once the above conditions are present, the formation of thunderstorms increases.

The above results show that in the winter the required conditions to form convention instability and thunderstorms are more possible in southwest parts as western winds and Mediterranean cyclones are dominant phenomenon in northwestern country. However, in the spring and summer, the conditions are more provided in northwest for retreat of the western winds and Mediterranean cyclones toward northern latitudes because of the residual humidity from the winter and the southern hillside heating of Zagros mountains in the spring provides conditions for local instabilities to occur therefore the maximum frequency of thunderstorm occurrence is observed in this region. In addition, the condition to form thunderstorms in southwest parts is more achievable in the autumn because of the surface heating and subtropical high pressure retreat toward the lower latitudes and presence of sufficient humidity. Furthermore, in an hourly scale, the required conditions for thunderstorm formation at night are more available in Persian Gulf and Oman Sea Coasts; however, the southern domains of Zagros Mountains are more Susceptible for thunderstorm development during the day.

\section{Conclusion}

Results show that the spatial distribution of thunderstorm in Iran is a function of time and topographical conditions of the considered region. According to the obtained results it can be noted that thunderstorm focus is more observed in southern domains of Zagros Mountains and then the frequency decreases by moving toward eastern parts. In the northern east of Iran, Torbat Heydarieh station revealed the maximum frequency among other adjacent stations which was related to the presence of high mountains like Qaenat Mountains in the region. In addition, in terms of temporal distribution, the maximum frequency of thunderstorm phenomenon occurs more in April and May in the spring. In this season, the most effective factor of ascending in the country is hillside convention. Maku station in northwestern Iran showed the maximum frequency of thunderstorm during the statistical period under study (mean annual 31 number) and Jask station experienced the least frequency of thunderstorm (mean annual 2 number). Also, the maximum frequency of thunderstorm phenomenon has happened during 12 to 18 o'clock in UTC time. This time interval complies with the afternoon hours and the maximum surface heating, and water evaporation to the atmosphere increases the buoyancy of air parcels ascending to the atmosphere and provides the conditions to form strong conventions and consequently the thunderstorms.

\section{References}

[1] Changnon, S.A. (2003) Thunderstorm Rainfall in the Conterminous United States. Bulletin of the American Meteorological Society, 82, 1925-1940. http://dx.doi.org/10.1175/1520-0477(2001)082<1925:TRITCU>2.3.CO;2

[2] Whiteman, C.D. (2003) Mountain Meteorology. Oxford University Press, London.

[3] Easterling, D.R. (1989) Regionalization of Thunderstorm Rainfall in the Contiguous U.S. International Journal of Climatology, 9, 567-579. http://dx.doi.org/10.1002/joc.3370090603

[4] Easterling, R. (2003) Trends in U.S. Climate during the Twentieth Century. American Meteorological Society, 12, 312.

[5] Gottlieb, R.J. (2009) Analysis of Stability Indices for Severe Thunderstorms in the Northeastern United States. M.Sc. Thesis, Cornell University, Ithaca, 146.

[6] Huff, F.A. (1964) Correlation between Summer Hail Patterns in Illinois and Associated Climatological Events. Journal of Applied Meteorology and Climatology, 3, 240-246.

[7] Callo, A. and Pascual, R. (2005) Diagnosis and Modelling of a Summer Convective Storm over Mediterranean Pyrenees. Advances in Geosciences, 2, 273-277. http://dx.doi.org/10.5194/adgeo-2-273-2005

[8] Adam, B.F., de Coning, E. and Bantiz, L. (1999) A Servere Weather Event on 29 December 1997: Synoptic and Mesoscale Perspectives. Water SA, 26, 137-146.

[9] Camuffo, D., Cocheo, C. and Enzi, S. (2000) Seasonality of Instability Phenomena (Hail Storms and Thunderstorms) in Padova, Northern Italy. From Archive and Instrumental Sources from AD 1300 to 1989. The Holocene, 10, 642-645. 
[10] Dayan, U., Margarit, Z.B. and Sharon, M.E. (2001) A Severe Autumn Storm over the Middle-East: Synoptic and Mesoscale Convection Analysis. Theoretical and Applied Climatology, 69, 103-122. http://dx.doi.org/10.1007/s007040170038

[11] Khoshhal, J. and Rahimighavidel, Y. (2007) Identify the Characteristics of the Environmental Disaster Area North West of Iran (Case Study: Risk of Thunder Storms in Tabriz). Quarterly Journal of the Humanities, 2007, 101-115.

[12] Hejazi-Zadeh, Z. (2000) Synoptic Factors Associated with Thunder Storms in the West Country. Journal of the Faculty of Literature and Humanities, 28, 1-17.

[13] Haghighat-Kashani, K. (1991) Frequency of Thunderstorms in Iran. MS Thesis, Department of Geography, University of Tehran.

[14] Tajbakhsh, S., Ghafariyan, P. and Mirzaei, E. (2008) A Method for Predicting the Occurrence of Thunder Storms with Two Case Studies. Journal of the Earth and Space Physics, 4, 147-166.

[15] Meteorological Institute of Iran (2006) Investigate the Occurrence of Avalanches, Thunderstorm, and Hail in Different Parts of Iran. Third Report, Vol. 1, Determine of Potential of Climate Disasters in the Country.

[16] Omidvar, K., Safarpoor, F. and Zangeneh-Inanloo, E. (2011) Synoptic Analysis Tuesday Severe Hail Events in Isfahan. Journal of Geography and Development, 30, 157-178. 